\title{
MINING LAND SUBSIDENCE MONITORING USING SENTINEL-1 SAR DATA
}

\author{
Weilin Yuan ${ }^{\mathrm{a}}$, Qun Wang ${ }^{\mathrm{b}}$, Jinghui Fan ${ }^{\mathrm{a}}$, Hongzhou $\mathrm{Li}^{\mathrm{c}}$ \\ ${ }^{a}$ China Aero Geophysical Survey and Remote Sensing Centre for Land and Resources, China, yuan_weilin@126.com \\ ${ }^{\mathrm{b}}$ School of Land Science and Technology, China University of Geosciences, China, wangq0723@163.com \\ ${ }^{\mathrm{c}}$ Satellite Surveying and Mapping Application Center, NASG, China, xiaozhou1208@163.com
}

KEY WORDS: DInSAR, Land Subsidence, Mining area, Sentinel-1, Interferogram

\begin{abstract}
:
In this paper, DInSAR technique was used to monitor land subsidence in mining area. The study area was selected in the coal mine area located in Yuanbaoshan District, Chifeng City, and Sentinel-1 data were used to carry out DInSAR techniqu. We analyzed the interferometric results by Sentinel-1 data from December 2015 to May 2016. Through the comparison of the results of DInSAR technique and the location of the mine on the optical images, it is shown that DInSAR technique can be used to effectively monitor the land subsidence caused by underground mining, and it is an effective tool for law enforcement of over-mining .
\end{abstract}

\section{INTRODUCTION}

Surface subsidence is a very common phenomena around mining area, and it has brought great difficulties to the economic development and environmental protection of the city. In China, the problems of land subsidence are very prominent, which directly endanger the ground construction facilities and the natural environment and affect the human living environment, local economic development, and even human life and property security. Therefore, it is important to monitor the surface subsidence of the mining area which can not only provide decision reference data for the environmental protection department and production management department, but also the disaster assessment and prevention (Perski 1998, Perski 2000). The monitoring of ground subsidence caused by underground mining relies mainly on traditional earth leveling, static GPS measurements or dynamic GPS measurements. However, these methods based on point measurements are difficult to obtain subsidence trends throughout the region and also require extremely high human and financial resources (Hebblewhite et al., 2000).

In recent years, space-to-ground remote sensing technology, especially satellite radar measurement technology has been rapidly developed. A large number of studies and application examples show that Synthetic Aperture Radar Differential Interferometry (DInSAR) can be applied to long-term slow surface deformation monitoring (Rodriguez et al., 1992, Carnec et al., 1996). DInSAR technique uses phase information of SAR images to extract the surface deformation, and its precision can reach the millimeter level, which also has unprecedented continuous space coverage, and highly automated capacity. It provides a new approach for the deformation of the surface automation monitoring (Chang et al., 2005, Colesanti et al., 2005, Liu et al., 2009). Relative to the traditional GPS and leveling measurements, the advantages of monitoring mining land subsidence using DInSAR technology are mainly in the following three points:

(1) Compared with GPS, DInSAR technology has the advantages of high sampling density, good spatial continuity and no need to establish ground receiving station.
(2) Compared with other monitoring displacement instruments, DInSAR technology is able to avoid the high cost of measuring instruments and lots of ground control points. It makes the monitoring of large area surface deformation easier.

(3) DInSAR, which is very sensitive to ground deformation, with high-precision ground deformation measurement capability and high spatial resolution detection capability, can be used to accurately determine the ground subsidence. At the same time, the method has unparalleled advantages compared to GPS, that makes it a useful complement to traditional monitoring methods. Moreover, it has a certain degree of continuity, which doesn't have to establish ground monitoring network.

Besides, DInSAR can acquire ground elevation and deformation information all-weather and all-day. In particularly, its measurement accuracy of up to millimeter-level potential and continuous space coverage, make it an useful method to monitoring long-term surface deformation. DInSAR has become a very potential space-to-ground observation technology. Therefore, the study of the application of DInSAR technique and its application in mining land subsidence monitoring has important application value and broad application prospect.

\section{THE SENSITIVITY OF INTERFEROMETRIC PHASE MEASUREMENT AND THE FEASIBILITY OF DEFORMATION DETECTION}

The change of interferometric phase depends on the topographic relief and surface deformation (surface motion). Using this principle we can extract ground elevation and detect surface deformation with differential SAR interferometry technology. Often people are confused of the different accuracies between the extraction of elevation using InSAR and surface deformation using DInSAR. Here, we explore the sensitivity of phase measurement relative to the elevation change and deformation and the relationship with several key parameters.

After taking the derivation of equation of deformation $\Delta \rho$, we can get the sensitivity of the phase to the terrain change:

$$
\frac{\partial \varphi^{\prime}}{\partial \theta}=\frac{4 \pi}{\lambda} B^{\prime} \cos \left(\theta-\alpha^{\prime}\right)
$$


Where the parameters are shown in the Fig.1. $B^{\prime}$ is spatial baseline, $\varphi^{\prime}$ is phase difference of $\rho_{1}$ and $\rho_{3}, \theta$ is looking angle.

Because of $h=H-\rho \cos \theta$, we can also derive $\partial h=\rho \sin \theta \cdot \partial \theta$, and then substitute it into the equation $(1)$,

$$
\frac{\partial \varphi^{\prime}}{\partial h}=\frac{4 \pi}{\lambda} \frac{B^{\prime} \cos \left(\theta-\alpha^{\prime}\right)}{\rho \sin \theta}
$$

Similarly, we can get the sensitivity of the phase to the surface deformation :

$$
\frac{\partial \varphi^{\prime}}{\partial \Delta \rho}=\frac{4 \pi}{\lambda}
$$

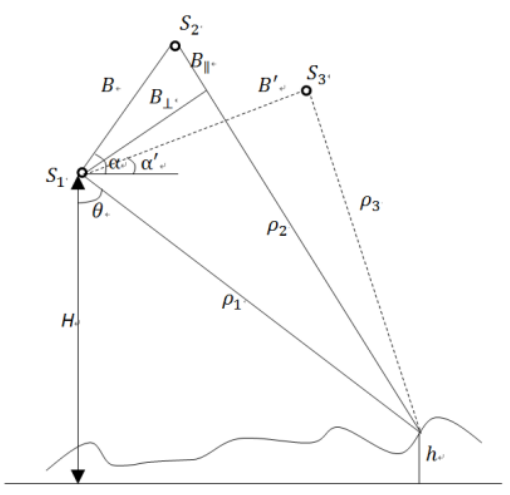

Fig.1 The basic principle of DInSAR

Compared equation (2) with equation (3), the right side of the equation (3) $\frac{4 \pi}{\lambda}$ is a constant for a SAR system. And the right side of the equation (2) equals to the constant multiply a fraction. The slant-range $\rho$ is much larger than the baseline $B$, so the value on the right side of equation (2) is much smaller than the value on the right side of equation (3). Therefore, the accuracy of DEM generated through InSAR technology can only reach a few meters in general. However, when used for detecting surface change, the phase to deformation accuracy can reach the level of centimeter or even millimeter. According to the different sensitivities of phase to terrain and deformation, it clearly illustrates that DInSAR has the ability to detect small surface deformation and movement.

\section{STUDY AREA AND DATA}

Yuanbaoshan District located in the eastern Inner Mongolia, with the area $952.14 \mathrm{~km}^{2}$, geographical coordinates of longitude $119^{\circ} \sim 119.5^{\circ}$, latitude $42^{\circ} \sim 42.5^{\circ}$. The elevation of Yuanbaoshan District varies from 500 to $700 \mathrm{~m}$. In Yuanbaoshan District geologists have found 14 coal, gold, copper, or iron ore, in which there are 5 medium-sized deposits, 1 small deposits, 5 mining points, 3 mineralization points. Oil and natural gas have considerable reserves. Coal reserves in this area is about 2 billion tons throughout 8 townships, with an annual output of nearly 10 million tons of coal. Currently there are cracks and faults appears on the ground, buildings and railway inYuanbaoshan District. Local government has devoted to the monitoring and recovering of such kind of subsidence, and preliminary results have been achieved.

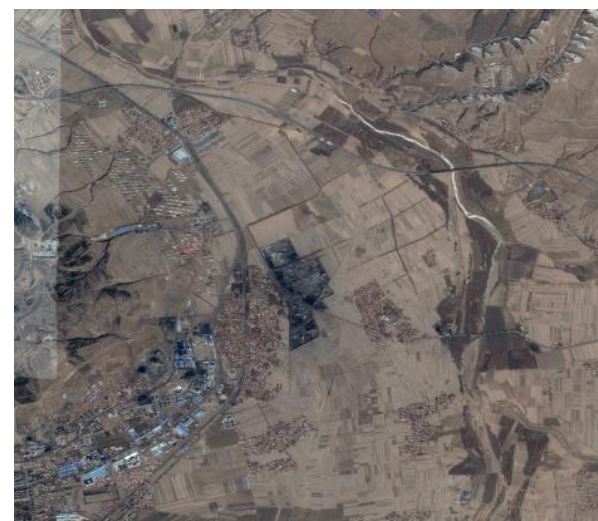

Fig.2 optical image of Yuanbaoshan District, Chifeng City, P.R.China

\subsection{Sentinel-1 data}

The Sentinel-1 system is a radar satellites constellation consisting of two C-band synthetic aperture radar sensors, Sentinel-1A and Sentinel-1B, with different resolution (down to $5 \mathrm{~m}$ ) and coverage (up to $400 \mathrm{~km}$ ). S-1A is the first satellite developed by the European Commission (EC) and the European Space Agency (ESA) for the Copernicus Global Earth Observation Project which was launched in April 2014. Sentinel-1 has short revisit time which can reach six days and provides dual polarization. The Sentinel-1 imaging parameters is shown in the table 1 .

\begin{tabular}{|c|c|c|c|c|}
\hline Modes & $\begin{array}{c}\text { Incident } \\
\text { angle }^{\circ}\end{array}$ & $\begin{array}{c}\text { Resoluti } \\
\text { on }(\mathrm{m})\end{array}$ & $\begin{array}{c}\text { Width } \\
/ \mathrm{km}\end{array}$ & $\begin{array}{c}\text { Polarizatio } \\
\mathrm{n}\end{array}$ \\
\hline SM,Stripmap & $20 \sim 45$ & $5 \times 5$ & 80 & $\begin{array}{l}\mathrm{HH}+\mathrm{HV}, \\
\mathrm{VH}+\mathrm{VV}, \\
\mathrm{HH}, \mathrm{VV}\end{array}$ \\
\hline $\begin{array}{c}\text { IW,Interfero } \\
\text { metric Wide } \\
\text { swath }\end{array}$ & $29 \sim 46$ & $5 \times 20$ & 250 & $\begin{array}{l}\mathrm{HH}+\mathrm{HV}, \\
\mathrm{VH}+\mathrm{VV}, \\
\mathrm{HH}, \mathrm{VV}\end{array}$ \\
\hline $\begin{array}{c}\text { EW,Extra } \\
\text { Wide swath }\end{array}$ & $19 \sim 47$ & $20 \times 40$ & 400 & $\begin{array}{l}\mathrm{HH}+\mathrm{HV}, \\
\mathrm{VH}+\mathrm{VV}, \\
\mathrm{HH}, \mathrm{VV}\end{array}$ \\
\hline
\end{tabular}

Table 1. Sentinel-1 parameters

Archived Sentinel-1 data are collected to handle from December 21, 2015 to May 25, 2016. The interferograms generated after data processing are shown in the Table 2 . We select SAR images as interferometric pairs with short time interval and small perpendicular baseline to obtain better results. The smaller the spatial baseline, the smaller the spectral offset, so the coherence of interferometric pairs increases. When time baseline is short, the changes on the ground affect the coherence of interferometric pairs weakly. All above reduce the loss of coherence.

\begin{tabular}{|c|c|c|c|}
\hline $\begin{array}{c}\text { Interferom } \\
\text { etric pair }\end{array}$ & $\begin{array}{c}\text { Master image } \\
\text {-slave image }\end{array}$ & $\begin{array}{c}\text { Perpendi } \\
\text { cular } \\
\text { Baseline } \\
(\mathrm{m})\end{array}$ & $\begin{array}{c}\text { Time } \\
\text { Baseline } \\
(\mathrm{d})\end{array}$ \\
\hline 1 & 20151221_20160102 & -13.72 & 12 \\
\hline 2 & 20151221_20160326 & 18.17 & 96 \\
\hline
\end{tabular}




\begin{tabular}{|c|c|c|c|}
\hline 3 & 20151221_20160419 & 21.31 & 120 \\
\hline 4 & 20151221_20160525 & -36.16 & 156 \\
\hline 5 & $20160102 \_20151127$ & 92.13 & 36 \\
\hline 6 & $20160114 \_20160207$ & 141.81 & 24 \\
\hline 7 & $20160114 \_20160326$ & 65.58 & 72 \\
\hline 8 & $20160114 \_20160407$ & 91.62 & 84 \\
\hline 9 & $20160114 \_20160419$ & 65.28 & 96 \\
\hline 10 & 20160114_20160606 & 69.83 & 144 \\
\hline 11 & 20160114_20161115 & 74.69 & 306 \\
\hline 12 & 20160126_20160219 & 102.06 & 24 \\
\hline 13 & 20160126_20160302 & 13.1 & 36 \\
\hline 14 & 20160126_20160314 & -28.88 & 48 \\
\hline 15 & 20160126_20160525 & 30.61 & 120 \\
\hline
\end{tabular}

Table 2. Sentinel-1 data for processing

\subsection{External DEM data}

The external DEM is SRTM (Shuttle Radar Topography Mission, 30m x 30m ground resolution) downloaded from the seamless data distribution system of the Earth Resources Observation and Science of USGS whose website address is http://srtm.csi.cgiar.org/SELECTION/inputCoord.asp (USGS Earth Resource Observation and Science (EROS) Center, 2016). The data cover the whole processing area in Yuanbaoshan District.

\section{RESULTS AND ANALYSIS}

Standard DInSAR technique is applied to every interferometric pairs listed in Tab. 2. Fig.3, Fig.4, Fig.5 are the typical results based on DInSAR technique using Sentinel-1 data.
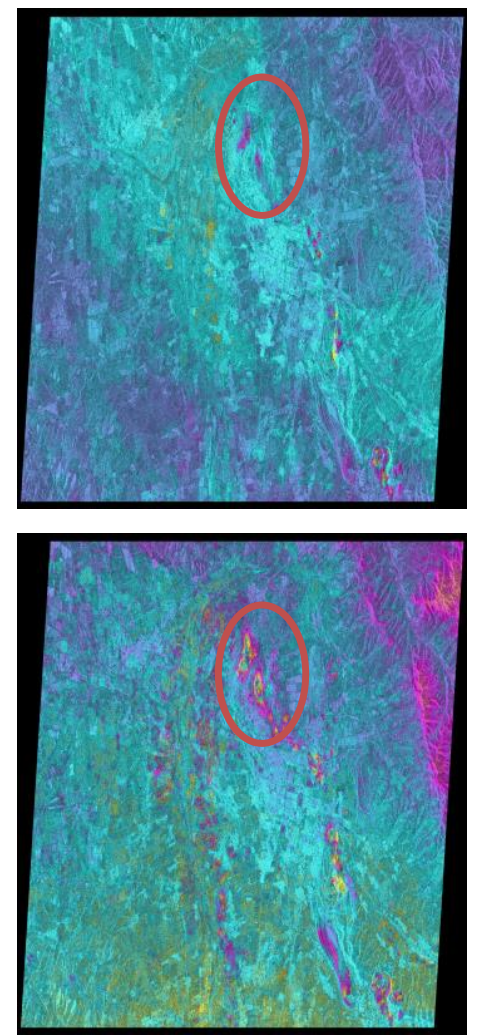

$-\pi$

A.20151221_20160102

B.20151221_20160326
Because of long time baseline and vegetation growth, some parts of the results are suffered from low coherence. We select two interferometric pairs on Fig.3A as an example to analysis. Fig.3A appears a half-cycle interferometric fringe in 12 days around the key mining area. Each interferometric cycle represents that the deformation is half of a wavelength. Because Sentinel-1 data is C-band whose wavelength is $56 \mathrm{~mm}$, the largest deformation is approximately $14 \mathrm{~mm}$ in Fig.3A. Fig.3B is the interferogram which has a common master image with fig. $3 \mathrm{~A}$ and the slave image whose imaging time is about three months later than that in fig. $3 \mathrm{~A}$. The interferometric circle with more than 2 cycles appears around the key mining area, indicating that the maximum deformation is more than $56 \mathrm{~mm}$.
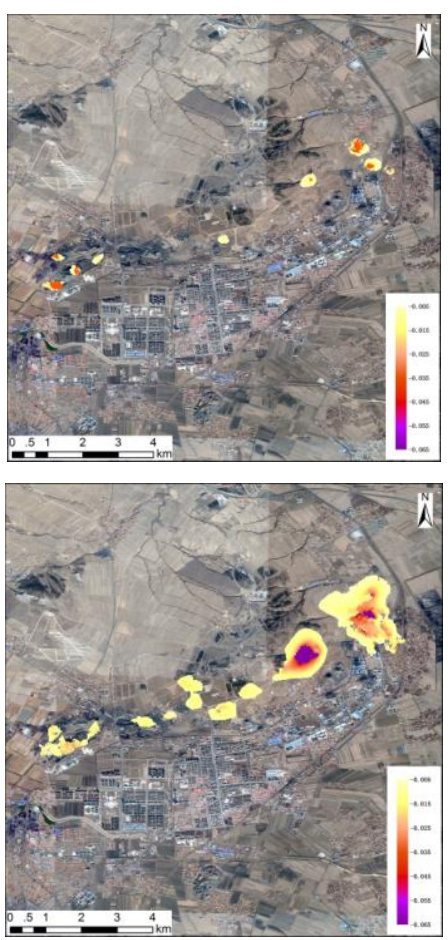

A.20151221_20160102

B.20151221_20160326

Fig.4 Mining subsidence results using DInSAR technique with Sentinel-1 data.

We focus on the deformation of the mining area and superimposed the results on the optical image. Then we can clearly see that the ground collapsed seriously around the mine in the Yuanbaoshan District, while other area such as residential area and arable land did not appear land subsidence. This indicates DInSAR technique is an effective means of monitoring land subsidence of mine. The optical data was shot on 22 February 2015, on which there was no sign of mining in the area where the serious deformation was shown on Fig.4B. It indicates that the coal mine at the top right of the picture begins to excavate at the end of 2015. In the about 3 months of excavation, a mining point on the ground caused more than $60 \mathrm{~mm}$ deformation on an area of 4 square kilometers. Through the comparison it is also shown that in the initial coal excavation, the land will have a greater collapse rate and the subsidence of the area will rapidly increase. With the development of mining activities, the rate of land subsidence and the area expansion would slow down.

Fig.3 Differential Interferograms of Sentinel-1 data 


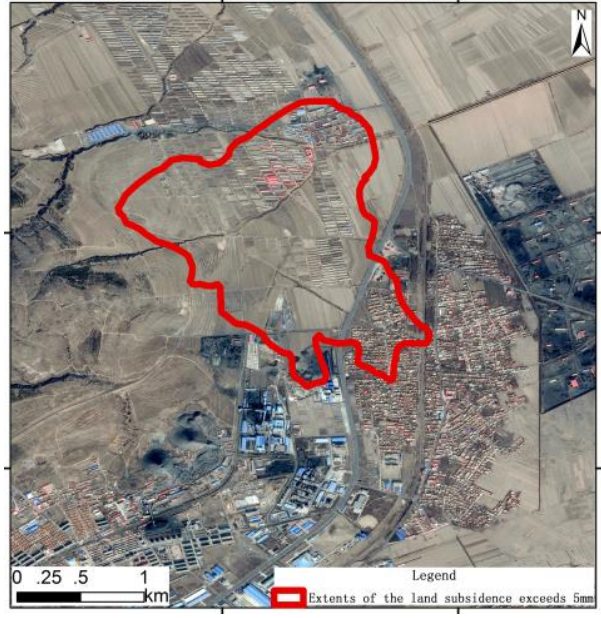

20151221_20160326

Fig.5 enlarged subsidence results

With the development of mine excavation activities, mining subsidence would cause a great impact on the surrounding environment. We can see that the land subsidence of the mining area has spread to the residential area, the road and the railway nearby. In Fig.5 Red border represents the extent of the land subsidence exceeding $5 \mathrm{~mm}$ which would affect the safety of buildings, highways and may cause major safety accidents. From the land subsidence on the residential area, the road and the railway around the mine, it can be speculated that underground cross-border excavation occurred in the area. Law enforcement agencies can easily judge whether mining company overlift or not through comparing the ground subsidence results with the scope of mineral rights.

\section{CONCLUSIONS}

The mine excavation activities could lead to land subsidence. DInSAR technique can monitor the land subsidence using the phase information of SAR images. By choosing interferometric pairs with small spatial baseline and time baseline in the same season, the coherence can preserve better. The application of DInSAR technique is of great importance for monitoring mine underground excavation. The results of DInSAR technique can be a basis for law enforcement officers when they survey that mining company whether has an underground cross-border excavation or not.

\section{ACKNOWLEDGE}

This work was supported by the second-level projects of China Geological Survey(Project No. DD20160342 and No. DD20160075 )

\section{REFERENCES}

Carnec, C., et al., 1996. "Two examples of the use of SAR interferometry on displacement fields of small spatial extent." Geophysical Research Letters, 23(24): 3579-3582.

Chang, H.-C., et al., 2005. DInSAR for mine subsidence monitoring using multi-source satellite SAR images. INTERNATIONAL GEOSCIENCE AND REMOTE SENSING SYMPOSIUM, Citeseer.

Colesanti, C., et al., 2005. "Detection of mining related ground instabilities using the Permanent Scatterers technique - a case study in the east of France." International Journal of Remote Sensing, 26(1): 201-207.

Hebblewhite, B., et al., 2000. Regional horizontal surface displacements due to mining beneath severe surface topography. 19th Int. Conf. on Ground Control in Mining.

Liu, G., et al., 2009. "Mining area subsidence monitoring using multi-band SAR data." Urban Remote Sens. Joint Event.

Perski, Z. 1998. "Applicability of ERS-1 and ERS-2 InSAR for land subsidence monitoring in the Silesian coal mining region, Poland." International Archives of Photogrammetry and Remote Sensing, 32: 555-558.

Perski, Z. 2000. "THE INTERPRETATION OF ERS-1 AND ERS-2INSAR DATA FOR THE MINING SUBSIDENCE MONITORING IN UPPER IN SILESIAN COAL BASIN, POLAND." International Archives of Photogrammetry and Remote Sensing, 33(B7/3; PART 7): 1137-1141.

Rodriguez, E. and J. Martin, 1992. Theory and design of interferometric synthetic aperture radars. IEE Proceedings $F$ (Radar and Signal Processing), IET.

USGS Earth Resource Observation and Science (EROS) Center., 2016. Global Data Explorer (GDEx) Data Access User Guide https://gdex.cr.usgs.gov/gdex/. 